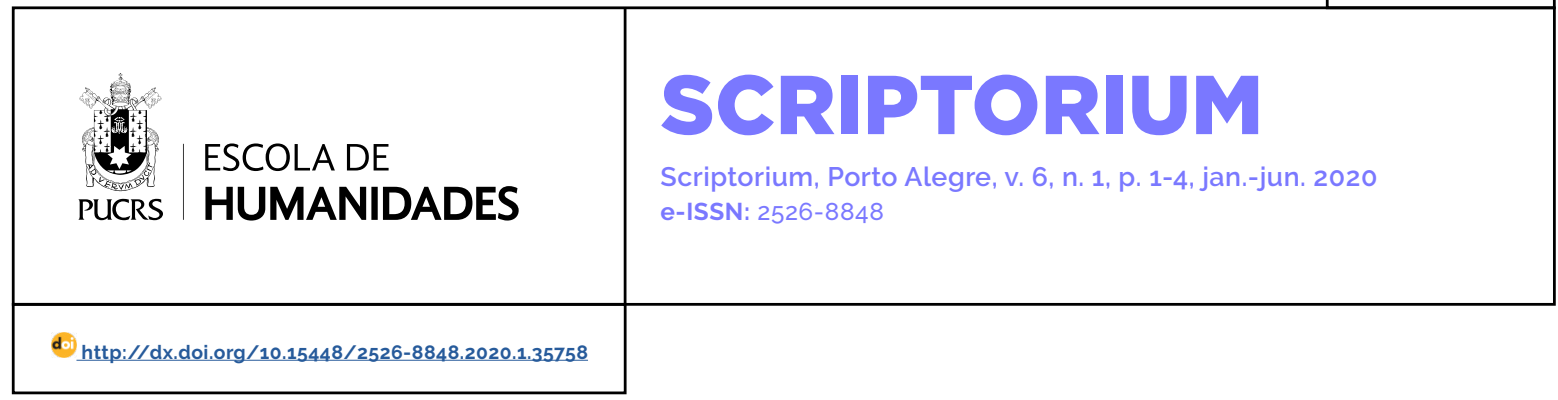

LIBERA

\title{
COMO UMA ONDA NO MAR: Ética e Criação Literária Através da Poesia
}

\section{Gisela Rodriguez ${ }^{1}$}

orcid.org/0000-0002-8901-3953

Gisela.Rodrigues@edu.pucrs.br

Recebido em: 18 set. 2019

Aceito em: 06 jan. 2020.

Publicado em: 20 jul. 2020.
Resumo: Nesse trabalho, o estilo ficcional de Dante Alighieri surge como o fio condutor de uma narrativa sobre os tópicos estudados nas aulas de filosofia, no Programa de Pós-Graduação em Letras. O texto é dividido em seis momentos: $1^{\circ}$ - o Prólogo, que introduz o leitor no "pensar sobre a linguagem"; $2^{\circ}$ - o Exilio, que ressalta a solidão inerente à criação literária; $3^{\circ}$ - a Realidade, que mostra as vicissitudes do oficio do escritor; $4^{\circ}$ - o Livro, que fala dos processos criativos e da ética na escritura; $5^{\circ}$ - a Alteridade, que aborda a importância do "outro" e a dialética e interdependência na produção artística; $6^{\circ}$ - a Despedida, no qual a autora comenta sobre o desapego da autoria, mostrando que o livro não pertence a ela e sim ao mundo. A criação dos versos segue o padrão das obras poéticas de Dante, mas o conteúdo discorre sobre as aulas ministradas pelo filósofo e professor Ricardo Timm de Souza. A linguagem, nesse caso, é um mecanismo para envolver o leitor numa narrativa inusitada, por trazer a referência de uma obra clássica, e ao mesmo tempo, a reflexão sobre as concepções contemporâneas de alteridade, autoria e ética na literatura.

Palavras-chave: Poesia. Escrita Criativa. Filosofia. Processos criativos. Apropriação.

Abstract: In this work, Dante Alighieri's fictional style emerges as a conductor of a narrative about the topics studied in philosophy classes in the Graduate Program in Letters. The text happens in six moments as an immersion in the writer's world: 1- Prologue: which introduces the reader to "thinking about language"; 2- In Exile: where the loneliness inherent in literary creation takes place; 3- The Reality: that shows the vicissitudes of the writer's work; 4- The Book: which speaks of creative processes and about ethics in scripture; 5- The Otherness: where the subject deals with the importance of the "other", the dialectic and the interdependence in the artistic production; 6- Farewell: in which the author explains about the need for detachment of the authorship, showing that the book does not belong to her, but to the world. The creation of the poetic text follows the pattern of Dante's poetic works, but the subjects dialogue with the classes of the philosopher and professor Ricardo Timm de Souza and also address the current reality. In this work, language is as a mechanism to engage the reader in an unusual narrative, by bringing the reference of a classic literature, and at the same time, the reflection on contemporary conceptions of otherness, authorship and ethics in the act of writing Keywords: Poetry. Creative Writing. Philosophy. Creative Processes. Appropriation.

Nada do que foi será de novo

Do jeito que já foi um dia

Tudo passa,

Tudo sempre passará

A vida vem em ondas como um mar

Num indo e vindo infinito

Tudo o que se vê não é

Igual ao que a gente viu há um segundo

Tudo muda o tempo todo no mundo Não adianta fugir, nem mentir pra si mesmo 


\section{CANTO I - Prólogo}

1. Inicio aqui o meu pensar sobre a linguagem, Jornada sem fim sob o prisma da morte Cuja embarcação é a minha própria viagem.

2. Assim sou levada pelo esquife fechado No turvo caminho de sinuosidade aquosa, Porque o espírito da escrita foi iniciado.

3. É preciso ir ao purgatório de Dante e trazer A morte e depois da morte é falar da vida,

E vida, para um escritor, é o ato de escrever.

4. Uma vida futura e uma morte presente Ou seria o contrário o que acontece;

Como saber o tempo certo dentro da gente?

5. Como escrever sem, verdadeiramente, morrer? ${ }^{1}$ Sendo a morte inerente à vida e sendo a vida Acontecimento regido pela capacidade de se envolver.

6. Através do amor me inclino a discorrer Sobre a escrita no sentido do gozo, da entrega, Do discurso amoroso inerente ao que vem a ser. 7. Peixe que submerge no ventre do oceano abissal, Circundado por golfinhos e cavalos brancos, Sob as sombras e miragens do espaço sideral.

8. Uivam meus sentidos de louco prazer Depois de açoitados pela inércia.

Deleitam-se agora com o ato de escrever.

9. Não há como ser peixe sem água, assim Como ser escritora sem a noção de alteridade. E a linguagem do espírito chega a mim.

\section{CANTO II - Exílio}

1. Direi as impressões do que agora reconheço Dessa minha vida em meio à escrita, Exilio a que me impus desde o começo.

2. No princípio era como um vale verdejante Se erguendo diante de mim, e desfrutava Aquela natureza, como Rousseau, o caminhante. 3. Misterioso crescimento se aproximava.

Eu ainda era uma criança nessa arte, Porém um sentimento penoso já me tragava. 4. E conto que em determinado instante Quando ainda me inclinava ao entendimento Sobre aquele lugar de atmosfera inebriante,

5. Pude ver através de meus ancestrais poetas E sentir-lhes a prisão escolhida por vontade própria Transformando-nos a todos numa espécie de asceta.
6. Por vezes, eu passava os dias debruçada Em minha mesa de artesã das palavras, Subvertendo um caos interno em histórias inventadas.

7. A mente vacilava entre ordem e perturbação,

Deixando-me ir para uma zona obscura.

E deparei-me com a minha própria obsessão.

8. Será falta de humildade essa busca pela perfeição?

Dizia a mim mesma enquanto os dias corriam

E folhas de papel acumuladas surtiam satisfação.

9. Nesse momento de vida, em tenra juventude Percebi que aquele ofício ao qual me empenhava Jamais me permitiria mudar de atitude.

10. Tudo o que restava era compreender Como lidar com aquela euforia e domar A selvageria mental que passei a conhecer.

11. Aquela nova vida que sobrevinha

E trazia o amadurecimento da alma,

Coexistia com a sensação de estar sozinha.

12. A literatura é um exilio intelectual²,

Percurso solitário, uma espécie de morte.

Emoção e razão tornam-se um espectro dual.

\section{CANTO III - Realidade}

1. Enquanto a lira da juventude me agradava, Seguia a concepção do tempo com outra visão. Nada ganhava com o trabalho a que me dedicava.

2. Precisava sustentar meus vícios com a arte, As viagens necessárias para a lógica do dia a dia, E ouvia "O tempo sem dinheiro é um tempo à parte."

3. Coisas do mundo dos homens, eu já sabia. Devoção ao devorador de seus herdeiros. O filho de Urano e de Gaia carregava sua profecia.

4. Nada podia fazer para libertar-me da falsa realidade.

Escravos da cronologia, criamos um monstro ${ }^{3}$, Que afugentava a quietude primitiva de nossa verdade.

5. A atmosfera terrestre era espetáculo excêntrico. As estrelas brilhavam menos enquanto eu permanecia

Em meio às construções de ferro e cimento.

6. Queria aprisionar Cronos, ir à sua captura,

E deleitar-me nas horas sem horas.

Tornar-me imortal mesmo tendo sepultura. 


\section{CANTO IV - O Livro}

1. No limbo me encontrava em estrada ardorosa Enganando a rotina com ironia poética,

E fui acometida por uma ideia engenhosa.

2. Relógio não é temporalé espacial ${ }^{4}$ - verdade pura E nós humanos, somos temporais e não espaciais, E é esse o tempo que tem de estar na literatura. ${ }^{5}$

3. Embora eu sustentasse o meu vinho e o meu pão, Ainda dependia da minha herança para sobreviver. Mas, decidi aceitar o meu quinhão.

4. Línguas vazias em discursos autoritários Haviam envenenado o meu sabor pela vida. Conto aqui como resolvi meus honorários.

5. Diziam aos quatro cantos algo peculiar: "Poesia não enche barriga e nem paga o aluguel." Cedendo aos caprichos sociais, resolvi trabalhar.

6. Passava "O tempo perdido" - Eu dizia -

Fazendo pães para vender de porta em porta, No "Tempo verdadeiro" escrevia da noite até o dia.

7. Descrevo sem receio sobre o intuito desse livro. Me agarrei a ele como uma loba aos seus filhotes, E o meu oficio se apresentava como algo vivo.

8. As palavras podiam ser torturantes,

Por vezes o pensamento se ressentia da sintaxe E da vontade de estilo, sempre cambiantes.

9. Tinha pena de mim por ser eu uma escrava Da própria vontade, para logo em seguida Perceber que a escravidão me deleitava.

10. Outras vezes eu era a amante, louca de paixão, E protegia aquele texto de qualquer amargura, Que porventura, viesse em momentos de exaustão.

11. Ao sacrificio acrescentava-se a festa da conquista; Liberdade no texto, transcendendo neuroses, criando

Novidades na linguagem, inventiva e otimista.

12. Uma obra sincera tem de conter algo de visceral. ${ }^{6}$ Ainda que nos encontremos sujeitados a tormentos E euforias, perturbando nossa saúde mental.

13. A crise inerente a esse drama que aqui relato, Pode parecer exagero, porém é sob o efeito Do conflito que acontece essa espécie de parto. 14. O nascimento do texto surge numa encruzilhada. Transformar a crise em critica.7 Sustentar as ideias No compasso do coração. Ir na raiz da palavra. ${ }^{8}$ 15. Por essa galáxia em espiral eu me transformei. A criação de uma nova realidade nas palavras
Levou minha alma a compreender outra lei: 16. Que a feitura do pão de todo o dia Minimizando o "ócio poético" aos olhos ordinários Trazia o mesmo prazer de quando eu escrevia. 17. Por mim passou a eternidade possível do louco. Por mim se foi o padecer do egoísmo.

Encontrando minha alma, despertei para o Outro. 18. A sabedoria de meu êxito vinha a contento.

O livro é o que luta para durar, apesar de tudo, alguma coisa ali resiste à lógica do tempo. ${ }^{9}$

\section{CANTO V - Alteridade}

1. Meu mestre veio a se tornar aquele ser Desconhecido que eu encontrava nas ruas. Era tudo agora o que eu precisava ver.

2. Da impossibilidade de morrer, e na evasão Cronológica, nasceu o mundo dentro de mim. Esfera celeste da consciência, nova percepção. 3. Transformei a negação do desejo e as frustrações De uma imortalidade impossivel, em escrita. Aproximei-me do Outro e suas visões.

4. "As coisas são sua história."10 - Ouvira falar. Encontrava-me nesse estado de espirito quando A vida alheia, com compaixão, comecei a observar.

5. A diferença que porventura traz descontentamento, E que nos faz pensar e nos coloca em dúvida, Torna-se união através do conhecimento.

6. Para chegar a outro lugar precisamos coexistir. ${ }^{11}$ Quando pergunto algo eu quero aprender ou ensinar? ${ }^{12}$

Talvez, antes de exatamente saber, pretendemos instruir.

7. O contrário também se faz importante: Ao responder uma pergunta eu aprendo; Minha própria reflexão se torna intrigante,

8. É um encantamento pedagógico que acontece. Uma presença é uma linguagem: explosão frutifera. O verdadeiro encontro é um susto que nos fortalece.

9. O ato de escrever contempla o Outro e a mim; E dessa dialética surge a obra de arte.

Criar é esse encontro inusitado e sem fim.

10. A vida espiritual humana deve ser vivida Para nos entranharmos na arte. É preciso

Que a essência do que nos rodeia seja atingida.

11. Através da linguagem encontrei minha essência; 
Meu próprio pensamento é uma linguagem anterior À língua que falo e escrevo: é a minha consistência. 12. Kant, o filósofo, dizia: "A obra de arte É onde a necessidade e a ética se misturam." Sem isso eu não podia chegar a nenhuma parte. 13. E para "eu ser eu", tornou-se primordial Transformar aquilo que me era comum, Em permanência na linguagem intelectual.

14. Toda a língua em algum sentido nomeia. A escrita é como uma inscrição na pedra; A irredutibilidade do texto criando a sua teia.

\section{CANTO VI - Despedida}

1. Quando cessou meu empenho e cheguei ao fim Do livro, o primeiro, senti-me tragada pelo cosmos. Algo havia morrido de alguma forma dentro de mim.

2. Em determinada noite, ou dia, nem lembro mais, Senti que precisava abdicar de algumas palavras. Fazia-se necessário tal golpe, e não as veria jamais.

3. Mais do que acrescentar, era tirar, até o limite; Entretanto, porvezes, uma única palavra excluida Destruía todo o sentido: O texto por si só existe.

4. Minha alma estava desnudada e assim sentia A obra libertada. Caminhos diferentes e infinitos, Olhos do universo. Meu livro a mim não pertencia. 5. Iniciou-se o fim daquela viagem, e outra começava. A essência espiritual humana é comunicável ${ }^{13}$, "O conteúdo da linguagem é ela mesma" pensava.

6. Minha viagem solitária chegara ao fim.

Mas permaneceria a sinceridade radical

Da obra, em outras pessoas, sem mim.

7. Quando desse profundo sono fui tirada,

Do poder criador da criação: a linguagem ${ }^{14}$. Reconheci que eu havia sido por ela convocada.

8. Escutei o eco daquele percurso profético:

Encontro do sonho com a realidade.

Se não fosse absurdo não seria poético ${ }^{15}$

\section{Citações}

Esse trabalho foi elaborado a partir das anotações feitas durante as aulas de Ética e Criação Literária I. Transcrevi em versos as minhas reflexões oriundas das falas do professor. Em citações, indico algumas frases ditas que não sofreram nenhuma alteração por mim, com o intuito de desenvolver o texto.

${ }^{1}$ SOUSA, Ricardo Timm. (anotação em aula)

SOUSA, Ricardo Timm. (anotação em aula)

3 SOUSA, Ricardo Timm. (anotação em aula)

4 SOUSA, Ricardo Timm. (anotação em aula)

5SOUSA, Ricardo Timm. (anotação em aula)

6SOUSA, Ricardo Timm. (anotação em aula)

7 SOUSA, Ricardo Timm. (anotação em aula)

${ }^{8}$ SOUSA, Ricardo Timm. (anotação em aula)

9SOUSA, Ricardo Timm. (anotação em aula)

${ }^{10}$ SOUSA, Ricardo Timm. (anotação em aula)

${ }^{11}$ SOUSA, Ricardo Timm. (anotação em aula)

${ }^{12}$ SOUSA, Ricardo Timm. (anotação em aula)

13 SOUSA, Ricardo Timm. (anotação em aula)

${ }^{14}$ SOUSA, Ricardo Timm. (anotação em aula)

${ }^{15}$ SOUSA, Ricardo Timm. (anotação em aula)

\section{REFERÊNCIAS}

ALIGHIERI, Dante. Divina comédia (1ํ volume). São Paulo: W. M. Jackson Inc. Editores, 1964.

ALIGHIERI, Dante. Divina comédia ( $2^{\circ}$ volume). São Paulo: W. M. Jackson Inc. Editores, 1964.

BARTHES, Roland. A preparação do romance (I - Da vida à obra). São Paulo: Martins Fontes, 2005.

SOUSA, Ricardo Timm. Ética do escrever (Kafka, Derrida e a literatura como crítica da violência). Porto Alegre: ZOUK, 2018

Gisela Rodriguez

Escritora e poeta. Doutoranda em Escrita Criativa PUCRS (Pontifícia Universidade Católica do Rio Grande do Sul) 